\title{
WT1 epitope-specific IgG and IgM antibodies for immune-monitoring in patients with advanced sarcoma treated with a WT1 peptide cancer vaccine
}

\author{
SHOUQ ALZAAQI ${ }^{1}$, NORIFUMI NAKA ${ }^{2}$, KENICHIRO HAMADA $^{3}$, NAOKI HOSEN $^{4}$, MIZUKI KANEGAE $^{1}$, \\ HIDETATSU OUTANI $^{5}$, MAYUKO ADACHI ${ }^{1}$, RIN IMANISHI ${ }^{1}$, EIICHI MORII ${ }^{6}$, MIKI IWAI ${ }^{1}$, JUN NAKATA ${ }^{1}$, \\ FUMIHIRO FUJIKI $^{7}$, SOYOKO MORIMOTO $^{8}$, HIROKO NAKAJIMA $^{7}$, SUMIYUKI NISHIDA $^{9}$, \\ AKIHIRO TSUBOI $^{10}$, YOSHIHIRO OKA ${ }^{8,9,11}$, HARUO SUGIYAMA ${ }^{7}$ and YUSUKE OJI ${ }^{1}$ \\ ${ }^{1}$ Department of Clinical Laboratory and Biomedical Sciences, Osaka University Graduate School of Medicine, \\ Suita, Osaka 565-0871; ${ }^{2}$ Department of Orthopaedic Surgery, Nachikatsuura Town Onsen Hospital, \\ Nachikatsuura, Wakayama 649-5331; ${ }^{3}$ Hamada Orthopaedic Surgery, Kawanishi City, Hyogo 666-0021; \\ Departments of ${ }^{4}$ Hematology and Oncology, ${ }^{5}$ Orthopaedic Surgery, ${ }^{6}$ Pathology, ${ }^{7}$ Cancer Immunology, \\ ${ }^{8}$ Cancer Stem Cell Biology, ${ }^{9}$ Respiratory Medicine and Clinical Immunology and ${ }^{10}$ Cancer Immunotherapy, \\ Osaka University Graduate School of Medicine, Suita, Osaka 565-0871; ${ }^{11}$ Department of Immunopathology, World Premier \\ International Research Center, Immunology Frontier Research Center, Osaka University, Suita, Osaka 565-0871, Japan
}

Received October 9, 2021; Accepted December 3, 2021

DOI: $10.3892 / \mathrm{ol} .2022 .13184$

\begin{abstract}
The Wilms' tumor gene WT1 is highly expressed in various malignancies and may be a common target antigen for cancer immunotherapy. In our group, peptide-based cancer vaccines targeting WT1 CTL epitopes were developed as an immunotherapy for these malignancies. In the present study, WT1 epitope-specific immune responses were analyzed in 31 patients with advanced sarcoma with human leukocyte antigen-A*24:02- and WT1-expressing tumors who received the WT1-235 peptide vaccine as monotherapy. The serum levels of IgG and IgM antibodies against the target epitope WT1-235 and the non-target epitopes WT1-332 and WT1-271 were measured using ELISA. IgM antibodies against WT1-235, WT1-332 and WT1-271 were detected in three $(9.6 \%)$, four $(12.9 \%)$ and 20 patients $(64.5 \%)$, respectively, prior to vaccine administration, indicating immune recognition of the WT1 antigen prior to administering the vaccine. Of 15 patients who had completed the 3-month treatment protocol, WT1-235 IgG was positive in five (33.3\%) patients. An enzyme-linked immunospot assay revealed that WT1-235 epitope-specific IL-10 production/secretion in peripheral blood mononuclear cells declined in the first month of vaccine administration in all three patients
\end{abstract}

Correspondence to: Professor Yusuke Oji, Department of Clinical Laboratory and Biomedical Sciences, Osaka University Graduate School of Medicine, 1-7 Yamada-oka, Suita, Osaka 565-0871, Japan E-mail: oji@sahs.med.osaka-u.ac.jp

Key words: WT1 antibody, WT1 peptide cancer vaccine, immunotherapy, immune monitoring, sarcoma with positivity for WT1-235 IgM at the start of the vaccine. Furthermore, positivity for both WT1-235 and WT1-271 IgM antibodies at the start of treatment was associated with unfavorable tumor control at 3 months after vaccine administration. These results suggested that WT1 epitope-specific IgG and IgM antibodies may be utilized as immune-monitoring markers for WT1 peptide cancer vaccine immunotherapy. The trials were entered in the University hospital Medical Information Network (UMIN) Clinical Trials Registry (https://www. umin.ac.jp/ctr; no. UMIN000002001 on May 24, 2009 and no. UMIN000015997 on December 20, 2014).

\section{Introduction}

Bone sarcomas (BSs) and soft-tissue sarcomas (STSs) are a heterogeneous group of mesenchymal malignancies with $>50$ histological subtypes. They are rare conditions, with estimated incidences of STS and BS averaging 4-5 and 1 per 100,000 cases per year, respectively, accounting for $\sim 1 \%$ of all malignancies (1). The rarity and diversity of sarcomas are critical hurdles in a better understanding of sarcomas and improving their therapeutic outcomes. The median overall survival for advanced leiomyosarcoma is $\sim 2$ years, but for most other advanced STS, it is shorter than 1 year and only $\sim 10 \%$ of patients survive for 5 years (2). Most STSs do not respond well to cytotoxic chemotherapy and their treatment options are limited and generally palliative, while the expected benefits are tempered by significant side effects. Therefore, novel therapeutic options are necessary to improve the clinical outcomes of sarcomas (3). Cancer immunotherapy is an attractive therapeutic approach, as it exerts anti-tumor effects through mechanisms different from those of conventional antitumor treatments. Thus, checkpoint inhibitors and adoptive T-cell 
therapies have been investigated as novel therapeutic options for sarcomas (3-6).

WT1 was initially isolated as a tumor suppressor gene responsible for Wilms' tumor, a pediatric renal neoplasm (7). However, WT1 is overexpressed in various cancer types, such as leukemia $(8,9)$, as well as lung $(10)$, colorectal (11), bone sarcoma and STS (12), and has been indicated to have oncogenic roles in these cancer types (13). Due to the tumor-specific expression and high immunogenicity of WT1, WT1-targeted immunotherapy has been considered a promising novel therapeutic strategy for various cancers. The WT1 protein is a ubiquitous tumor-associated antigen (TAA) and ranks as the top protein in terms of clinical immunotherapy usefulness among 75 TAAs (14). Consequently, our and other groups have demonstrated the clinical utility of WT1-targeted immunotherapies in multiple forms as a WT1 peptide cancer vaccine (15-24), WT1 peptide-pulsed or WT1 mRNA-electroporated dendritic cell vaccine $(25,26)$ and WT1-specific $\mathrm{T}$-cell receptor-transduced $\mathrm{T}$-cell therapy $(27,28)$.

The induction of an immune response against the target antigen is essential for clinical efficacy in WT1-targeted cancer immunotherapy. In previous studies by our group, the delayed-type hypersensitivity skin reaction and IgG antibody production against a WT1 peptide were analyzed to evaluate the induction of WT1-specific immune responses after administering the WT1 peptide vaccine $(15,16,18-23)$. The WT1 peptide IgG antibody has been examined as an immuno-monitoring marker indicating the activation of WT1-specific T helper cell (Th) responses by the WT1 peptide vaccine. Considering the essential roles of $\mathrm{Th}$ cells in the induction and maintenance of anti-tumor immune responses, the WT1-235 peptide IgG correlates with longer survival and may be a predictive marker in patients with recurrent glioblastoma treated with the WT1-235 peptide vaccine (29). Furthermore, B cells have been reported to correlate with a good prognosis of patients with sarcoma receiving immunotherapy. Petitprez et al (30) reported that the presence of B cells in the tumor microenvironment is the strongest prognostic factor for STS. These results indicate the essential roles of B cells and humoral immune responses in immunotherapy for sarcoma. However, the importance of humoral immunity, including B-cell functions, in the efficacy of the WT1 peptide vaccine remains undetermined. $\operatorname{Ig} M$ is the first antibody isotype expressed during B-cell development and the first humoral antibody response; furthermore, its production does not require Th cells. Therefore, epitope-specific IgM antibodies may also be helpful monitoring tools for humoral immune responses to tumor antigens.

In the present study, the serum levels of $\operatorname{IgG}$ and $\operatorname{IgM}$ against WT1 epitopes were examined in WT1-235 peptide vaccine-treated sarcoma patients, focusing on the humoral immune responses prior to WT1 peptide vaccine treatment. The WT1 epitopes examined included WT1-235, the target epitope of the vaccine, and two non-target WT1 epitopes, WT1-332 and WT1-271. The association between WT1 epitope-specific antibodies and WT1-235-specific cellular immune responses in the first month of vaccine therapy, as well as the clinical outcomes of vaccine therapy, were also analyzed.

\section{Materials and methods}

WT1-235 peptide cancer vaccine. WT1-235 peptide vaccine immunotherapy was administered with approval from the Ethical Review Board of the Osaka University Faculty of Medicine (Osaka, Japan). The eligibility criteria included the following: Histologically confirmed sarcoma not amenable to potentially curative therapies, WT1 protein expression in tumor cells, human leukocyte antigen (HLA)-A*24:02 positivity, age range of 16-85 years and good organ function. The Good Manufacturing Practice-grade, 9-mer modified WT1-derived peptide (mWT1-235; 235-243 a.a., CYTWNQMNL; Peptide Institute and Multiple Peptide Systems) was used for immunization. Patients were intradermally administered $3 \mathrm{mg}$ of mWT1-235 peptide emulsified with Montanide ISA51 adjuvant (Seppic) once per week for 12 consecutive weeks. After the 3-month treatment protocol, the WT1 peptide vaccine immunotherapy was continued until disease progression or intolerable adverse events were observed. Trials were registered at the University hospital Medical Information Network (UMIN) Clinical Trials Registry (https://www.umin.ac.jp/ctr) as UMIN000002001 (registered on May 24, 2009) and then UMIN000015997 (registered on December 20, 2014). The present study was approved by the ethical review board of the Faculty of Medicine, Osaka University (Osaka, Japan). Written informed consent was obtained from the participants at Osaka University Hospital (Osaka, Japan). These clinical trials are one-armed and therefore do not adhere to the Consolidated Standards Of Reporting Trials statement (31). The present study was performed in accordance with the Japanese Ethical Guidelines for Medical and Biological Research Involving Human Subjects.

Patient assessment. Antitumor effects were assessed by determining the response of target lesions on CT scans according to the Response Evaluation Criteria in Solid Tumors v1.0 (32). When tumor progression was slowing or inhibited during the treatment protocol period, WT1 peptide vaccination was continued after the 3-month protocol, mostly at intervals of 2-4 weeks. Safety was assessed by monitoring and recording adverse events, vital signs, clinical chemistry, hematology and urinalysis. Adverse events were graded according to the Common Terminology Criteria for Adverse Events v3.0 (33).

Serum samples. Sera were obtained with written informed consent from the patients at Osaka University Hospital (Osaka, Japan) at the indicated time-points. Serum samples were stored at $-20^{\circ} \mathrm{C}$ until use.

Peripheral blood mononuclear cell (PBMC) samples. Blood samples were obtained with written informed consent from the patients. PBMCs were isolated from heparinized whole blood using the standard Ficoll-Paque separation method and were cryopreserved in liquid nitrogen until use.

ELISA. WT1 epitope-specific $\operatorname{IgG}$ and $\operatorname{IgM}$ antibodies in serum were measured by ELISA as described previously (29). The amino acid sequences of the capture antigen peptides for WT1-235, WT1-325 and WT1-271 antibodies were CMTWNQMNLPKK, CAYPGCNKRYFKLSHLQM 
and YESDNHTTPILCGAQYRI, respectively. The peptides were synthesized by PH Japan. Using a peptide coating kit (cat. no. MK100; Takara Bio, Inc.), WT1 peptides or citrate (negative control) were immobilized on the bottom surface of each well as capture antigens, according to the manufacturer's instructions. After blocking with 1X Blocking One (Nacalai Tesque), patient sera diluted 1:100 with the blocking buffer from the peptide coating kit were added to each well and incubated at $4^{\circ} \mathrm{C}$ overnight. All serum samples were measured in duplicate. After washing with Tris-buffered saline containing Tween-20 (TBST), horseradish peroxidase (HRP)-conjugated rabbit anti-human IgG (cat. no. 309-035-003; Jackson ImmunoResearch Europe, Ltd.) or HRP-conjugated goat anti-human IgM antibody (cat. no. A80-100P; Bethyl Laboratories, Inc.), diluted at 1:2,000 in TBST, was added to each well and incubated at room temperature for $2 \mathrm{~h}$. After washing with TBST, corresponding third antibody, HRP-conjugated goat anti-rabbit IgG (cat. no. ab6721; Abcam) or HRP-conjugated rabbit anti-goat IgG antibody (cat. no. 546; MBL International Co.), diluted 1:5,000 in TBST, was added to each well and incubated at room temperature for $2 \mathrm{~h}$. Bound WT1 epitope-specific IgG or IgM antibodies were colorimetrically detected using 3,3',5,5'-tetramethylbenzidine substrate (KPL, Inc.). The absorbance was measured at $450 \mathrm{~nm}$ using a microplate reader (MULTISKAN FC; Thermo Fisher Scientific, Inc.). The antibody titer for each serum sample was determined as the average absorbance value of the duplicate wells after subtracting the absorbance value of the negative control well. The cutoff levels for positivity for WT1-235 IgM, WT1-235 IgG, WT1-271 IgM, WT1-271 IgG, WT1-332 IgM and WT1-332 IgG were set at 0.10, 0.15, 0.13, 0.06, 0.06 and 0.15 , respectively, based on the absorbance values of the mean $+3 \mathrm{x}$ standard deviation from five independent assays in negative control serum samples.

Enzyme-linked immunospot (ELISPOT) assay. After hydrophilization, the bottom membrane of each well in a 96-well filtration plate (Merck KGaA) was incubated with capture antibodies, including anti-human IFN- $\gamma$ monoclonal antibody (anti-human IFN- $\gamma$ mAb 1-D1K; final concentration, $15 \mu \mathrm{g} / \mathrm{ml}$ in PBS; cat. no. 3420-3-250; Mabtech AB) and anti-human IL-10 monoclonal antibody (anti-human IL-10 mAb; final concentration, $15 \mu \mathrm{g} / \mathrm{ml}$ in PBS; cat. no. 3430-3-250; Mabtech $\mathrm{AB})$, at $4^{\circ} \mathrm{C}$ overnight. After blocking the membranes with 1X Blocking One (cat. no. 03953-95; Nacalai Tesque, Inc.) at $37^{\circ} \mathrm{C}$ for $2 \mathrm{~h}$, thawed PBMCs suspended in FBS-free RPMI1640 medium $\left(5 \times 10^{4}\right.$ cells per $100 \mu$; Nacalai Tesque, Inc.) were seeded in each well in triplicate and the antigen peptide was added to the medium at a final concentration of $10 \mu \mathrm{g} / \mathrm{ml}$. The cells were incubated for antigenic stimulation at $37^{\circ} \mathrm{C}$ for $48 \mathrm{~h}$. After removing the cell suspension, each membrane was incubated with the corresponding detection antibodies: A biotinylated anti-human IFN- $\gamma$ monoclonal antibody (final concentration, $1.3 \mu \mathrm{g} / \mathrm{ml}$; cat. no. 3420-6-250; Mabtech AB) and a biotinylated anti-human IL-10 monoclonal antibody (final concentration, $1.3 \mu \mathrm{g} / \mathrm{ml}$; cat. no. 3430-6-250; Mabtech AB) in PBS containing $1 \%$ bovine serum albumin (Nacalai Tesque, Inc.) and $0.05 \%$ Tween-20 at $4^{\circ} \mathrm{C}$ overnight. After washing with PBS, each membrane was incubated with alkaline phosphatase-conjugated streptavidin (diluted
1:500 with PBS containing 0.05\% Tween-20; cat. no. 3310-8; Mabtech $\mathrm{AB}$ ) at room temperature for $1 \mathrm{~h}$. After washing both sides of the membranes, the spots were colored using 5-bromo-4-chloro-3-indolyl phosphate/nitro blue tetrazolium solution (Nacalai Tesque, Inc.), followed by washing with deionized water. After drying at $4^{\circ} \mathrm{C}$ overnight, the membranes were punched out using an acrylic device 'ELI 8' (Create Ltd.) onto a scotch tape. The membranes were then sandwiched with another strip of scotch tape and scanned with a scanner (Canoscan LiDE200; Canon, Inc.) at a resolution of 1,200 dpi. The generated digital images were analyzed for spot counting with the assistance of particle analysis using Image J software (version 1.50i; National Institutes of Health). WT1 antigen-specific IFN- $\gamma$ or IL-10 production/secretion by PBMCs was described as the antigen-specific immune response (IR) index as follows: (Number of spot-forming cells under antigen-stimulated test conditions)/(number of spot-forming cells under antigen-free control conditions) (34). The cutoff level for positive detection of antigen-specific cytokine production/secretion was 1.0 in the IR index.

Statistical analysis. Differences in the WT1-235 IgM, WT1-235 IgG, WT1-271 IgM, and WT1-271 IgG antibody titers were analyzed using Welch's t-test. The antibody titers were expressed as the mean of duplicated assay results in dot plots. The association between WT1 antibody production and clinical outcomes was analyzed using Fisher's exact probability test and Cramer's V-test. $\mathrm{P}<0.05$ was considered to indicate a statistically significant difference in Welch's t-test and Fisher's exact probability test. A P-value of 0.20-0.29 was considered to indicate moderate association in Cramer's V-test. The statistical analysis was performed using Statcel4 EXCEL Addin software (OMS Publishing Ltd.).

\section{Results}

Patient characteristics. In the present study, WT1 epitope-specific humoral immune responses were analyzed in 31 patients (21 male and 10 female patients; age range, 16-79 years; median age, 36 years) with advanced sarcoma out of 33 patients who participated in the clinical trial between April 2004 and November 2012, which was due to sample availability. These included various types of sarcomas, such as osteosarcoma, chondrosarcoma, rhabdomyosarcoma, clear cell sarcoma and Ewing's sarcoma. Of these 31 patients, 15 completed the 3-month treatment protocol, whereas the treatment of the remaining 16 was discontinued owing to disease progression; however, no adverse events were encountered (Table I). The treatment period was 1-1,387 days (median, 85 days). No severe WT1-235 peptide-related adverse events were observed.

Representative case. Details of a representative case are provided in Fig. 1. A 79-year-old male patient with leiomyosarcoma had previously undergone two surgical resections but was diagnosed with a second recurrence (patient ID, 28). The tumor lesion included a tumor adjacent to the right iliopsoas muscle. The patient refused further surgical resection with amputation of the right lower extremity and visited our hospital to receive the WT1-235 peptide cancer vaccine. As 
Table I. Patient characteristics.

\begin{tabular}{|c|c|c|c|c|c|}
\hline Patient ID & Age, years & Sex & Disease & Tumor control & Vaccine period (days) \\
\hline 1 & 68 & M & UPS & PD & 141 \\
\hline 2 & 21 & M & PNET & PD & 39 \\
\hline 3 & 27 & M & Fibrosarcoma & $\mathrm{PD}$ & 29 \\
\hline 4 & 18 & M & PNET & $\mathrm{PD}$ & 15 \\
\hline 5 & 63 & M & Chondrosarcoma & $\mathrm{PD}$ & 1 \\
\hline 6 & 16 & F & Mesenchymal chondrosarcoma & SD & 1,050 \\
\hline 7 & 51 & M & Clear cell sarcoma & PD & 78 \\
\hline 8 & 26 & M & DSRCT & PD & 43 \\
\hline 9 & 18 & M & DSRCT & SD & 253 \\
\hline 10 & 39 & M & Rhabdomyosarcoma & PD & 22 \\
\hline 11 & 33 & M & Chondrosarcoma & $\mathrm{PD}$ & 99 \\
\hline 12 & 36 & $\mathrm{~F}$ & Malignant schwannoma & SD & 869 \\
\hline 13 & 59 & $\mathrm{~F}$ & Liposarcoma & $\mathrm{PD}$ & 49 \\
\hline 14 & 31 & M & Osteosarcoma & NE & 121 \\
\hline 15 & 57 & M & UPS & $\mathrm{PD}$ & 71 \\
\hline 16 & 41 & $\mathrm{~F}$ & Rhabdomyosarcoma & $\mathrm{NE}$ & 379 \\
\hline 17 & 20 & M & Ewing's sarcoma & $\mathrm{NE}$ & 29 \\
\hline 18 & 19 & $\mathrm{~F}$ & Ewing's sarcoma & $\mathrm{NE}$ & 35 \\
\hline 19 & 55 & M & Undifferentiated sarcoma & $\mathrm{PD}$ & 545 \\
\hline 20 & 60 & M & Chondrosarcoma & $\mathrm{PD}$ & 433 \\
\hline 21 & 35 & M & Osteosarcoma & $\mathrm{PD}$ & 85 \\
\hline 22 & 59 & $\mathrm{~F}$ & UPS & PD & 99 \\
\hline 23 & 33 & $\mathrm{~F}$ & Clear cell sarcoma & $\mathrm{PD}$ & 85 \\
\hline 24 & 34 & M & Osteosarcoma & $\mathrm{PD}$ & 43 \\
\hline 25 & 42 & $\mathrm{~F}$ & UPS & $\mathrm{PD}$ & 36 \\
\hline 26 & 21 & M & Rhabdomyosarcoma & NE & $1,387+$ \\
\hline 27 & 37 & M & Osteosarcoma & $\mathrm{PD}$ & 92 \\
\hline 28 & 79 & M & Leiomyosarcoma & $\mathrm{SD}$ & $1,072+$ \\
\hline 29 & 24 & M & Osteosarcoma & $\mathrm{PD}$ & 15 \\
\hline 30 & 74 & $\mathrm{~F}$ & Leiomyosarcoma & $\mathrm{PD}$ & 106 \\
\hline 31 & 59 & F & Chordoma & $\mathrm{PD}$ & 183 \\
\hline
\end{tabular}

Patients with sarcoma were treated with the WT1-235 peptide cancer vaccine once per week for 12 consecutive weeks. After the 3-month treatment protocol, WT1 peptide vaccine immunotherapy was continued until disease progression or intolerable adverse events were observed. Tumor control was determined after 3 months of administering the WT1-235 peptide cancer vaccine. UPS, undifferentiated pleomorphic sarcoma; PNET, primitive neuroectodermal tumor; DSRCT, desmoplastic small round cell tumor; PMT, malignant phosphaturic mesenchymal tumor; $\mathrm{PD}$, progressive disease; $\mathrm{SD}$, stable disease; NE, not evaluated; M, male; F, female.

he met the criteria for the trial, the WT1-235 peptide cancer vaccine was started as a monotherapy. The tumor remained stable during the 3-month treatment period and the WT1-235 peptide vaccine was continued for $>3$ years. A slight enlargement of the tumor was observed during this period (Fig. 1).

Production of WT1-235 CTL epitope-specific IgG and IgM antibodies. To analyze the humoral immune responses to the WT1-235 CTL epitope, which is the target antigen of the WT1 peptide cancer vaccine, serum IgG and IgM antibodies against the WT1-235 peptide were examined. The WT1-235 IgG antibody was undetectable in all cases examined prior to vaccine treatment. The WT1-235 IgG antibody levels were significantly elevated and became positive in five patients at 3 months after the start of treatment. By contrast, WT1-235 IgM antibody levels were positive at the start and remained stable during the 3-month treatment protocol in three $(9.6 \%)$ of the 31 patients. Furthermore, one patient exhibited a transient increase in serum WT1-235 IgM antibody levels. The remaining 27 patients were negative for the WT1-235 IgM antibody during the 3-month protocol treatment. After 3 months of vaccination, the WT1-235 IgM antibody levels were significantly lower than before vaccine initiation (Fig. 2A). The 15 patients who completed the protocol treatment were divided into four groups based on the production of WT1-235 IgG and IgM antibodies as follows: i) WT1-235 IgM was positive prior to vaccination and WT1 IgG was negative after vaccination (WT1-235 IgM Pos/IgG Neg; n=3); 
A

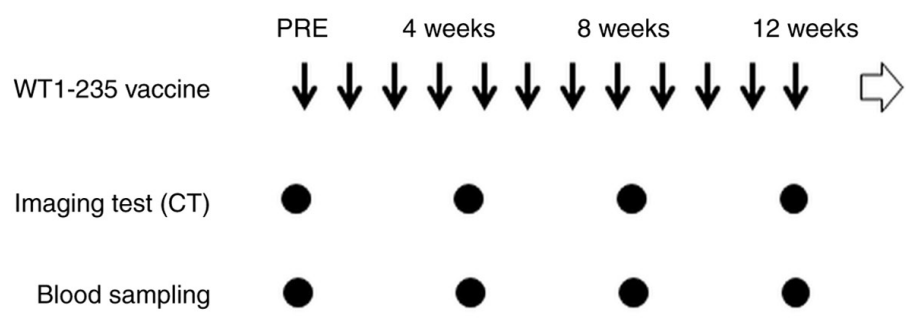

B

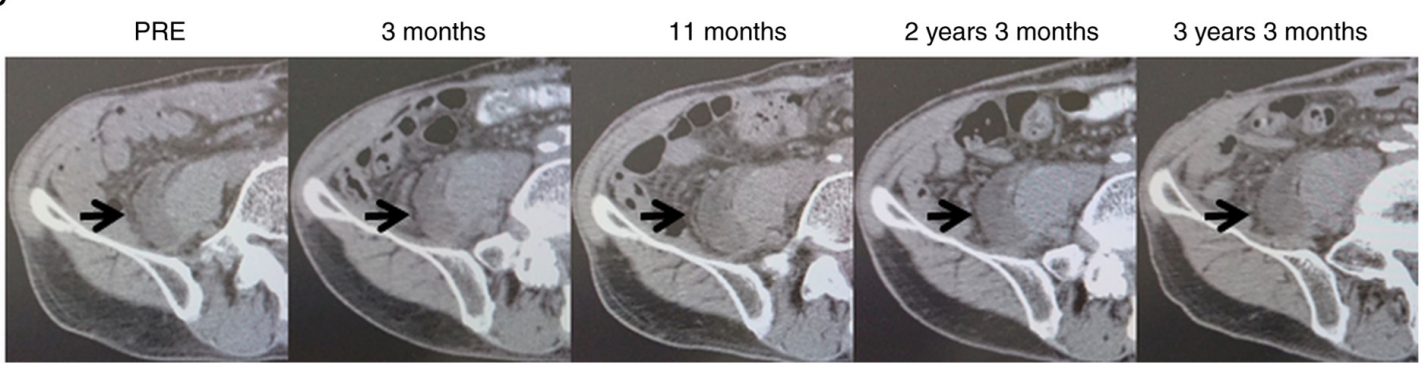

Figure 1. A leiomyosarcoma case treated with WT1-235 peptide cancer vaccine. (A) WT1-235 peptide vaccine schedule. (B) CT scanning images of the representative case (79-year-old male). Arrows indicate the tumor adjacent to the right iliopsoas muscle. PRE, pre-treatment; w, weeks; M, months; y, years.

B

A

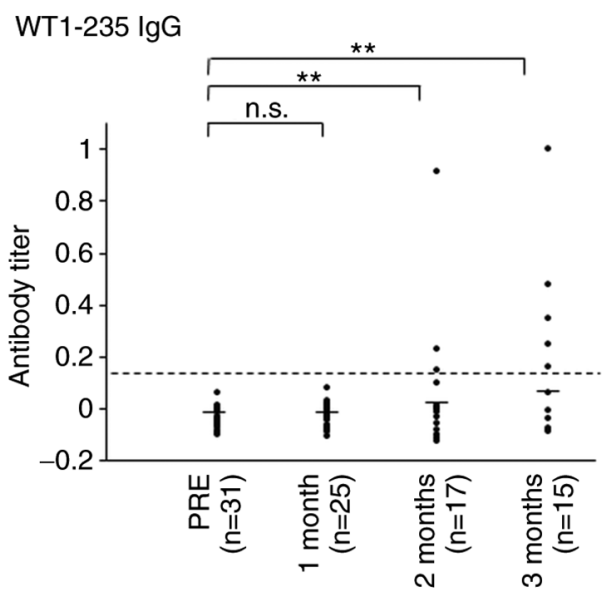

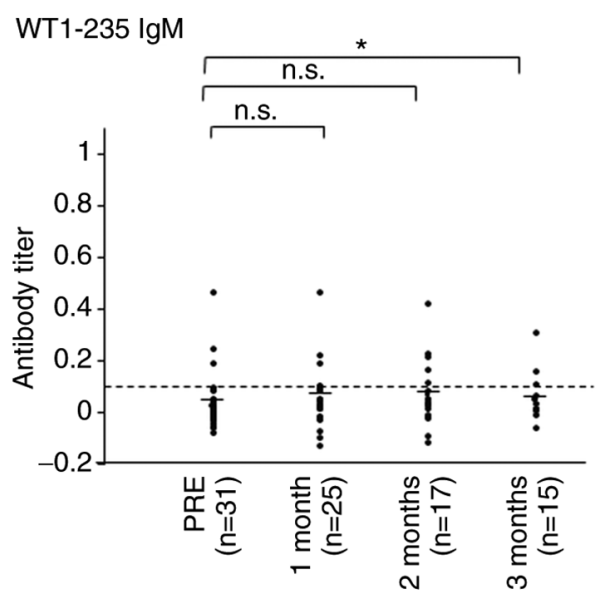
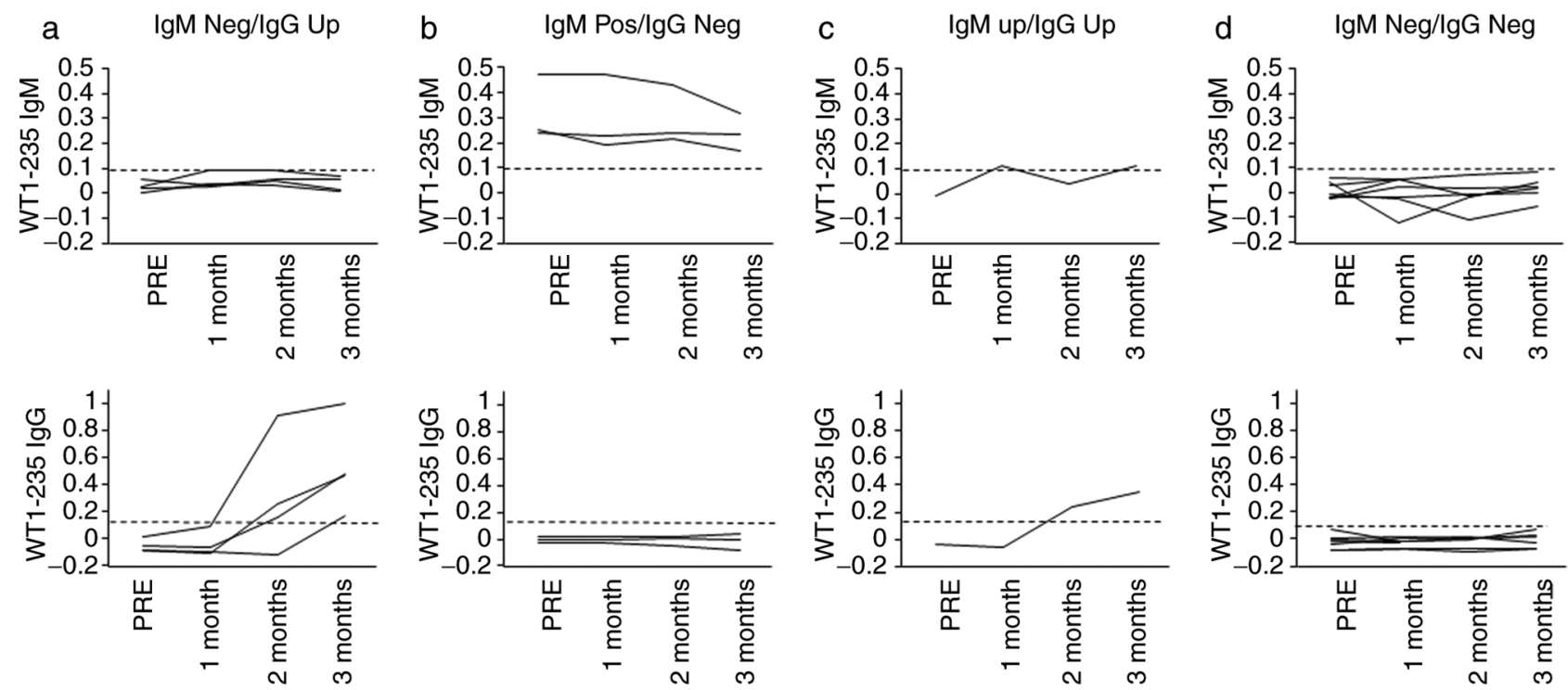

Figure 2. Production of WT1-235 CTL epitope-specific IgG and IgM antibodies. Blood samples were collected from the indicated number of patients at the designated time-points. The serum levels of WT1-235 IgG and IgM antibodies were measured using ELISA. Antibody titers are presented as the absorbance at $450 \mathrm{~nm}$. (A) Dot plots for serum levels of WT1-235 IgG and IgM antibodies. Horizontal bar, median value of antibody titer. ${ }^{*} \mathrm{P}<0.05,{ }^{* *} \mathrm{P}<0.01 ; \mathrm{n} . \mathrm{s}$., not significant. (B) Changes in serum WT1-235 IgM and IgG antibody levels in four groups stratified by the pattern of antibody production. Neg, negative; Pos, positive; Up, upregulated; PRE, pre-treatment; M, months. 
A

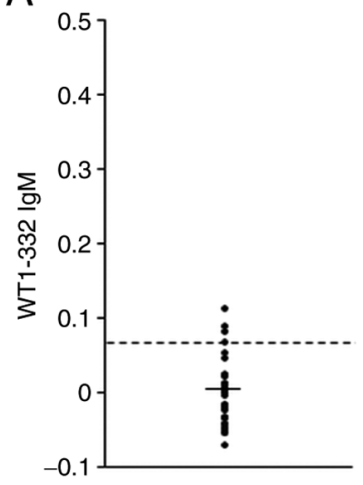

B

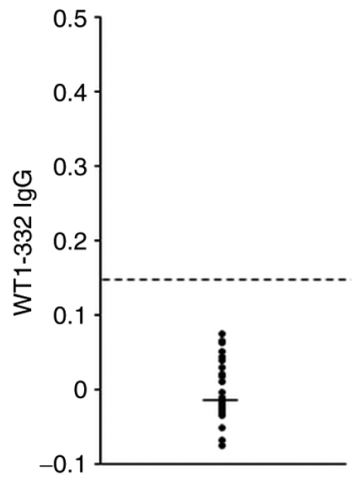

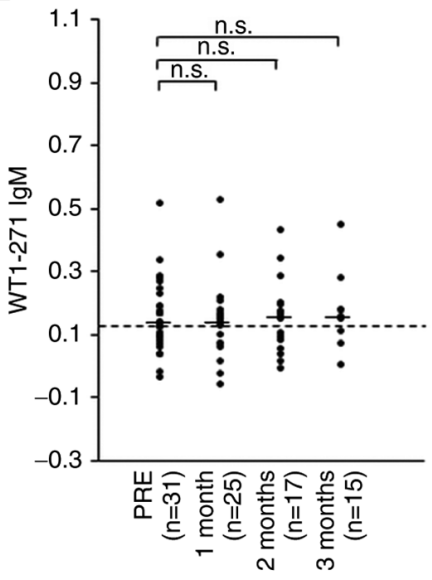

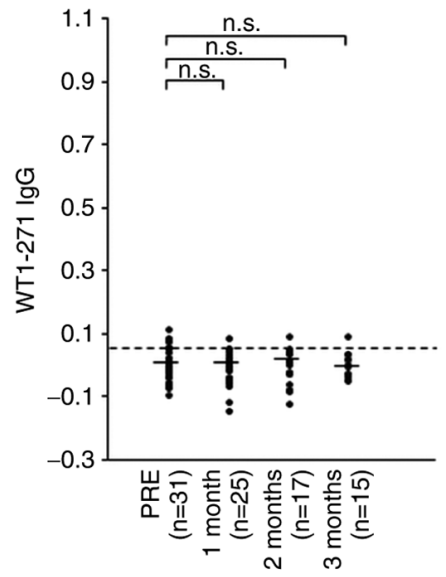

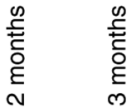

C

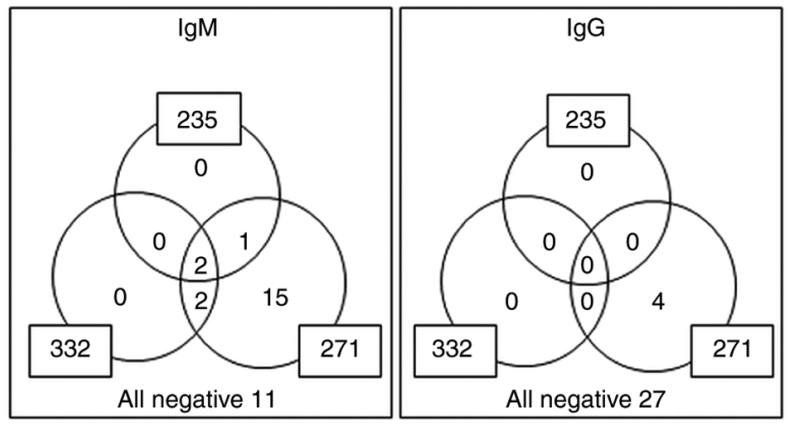

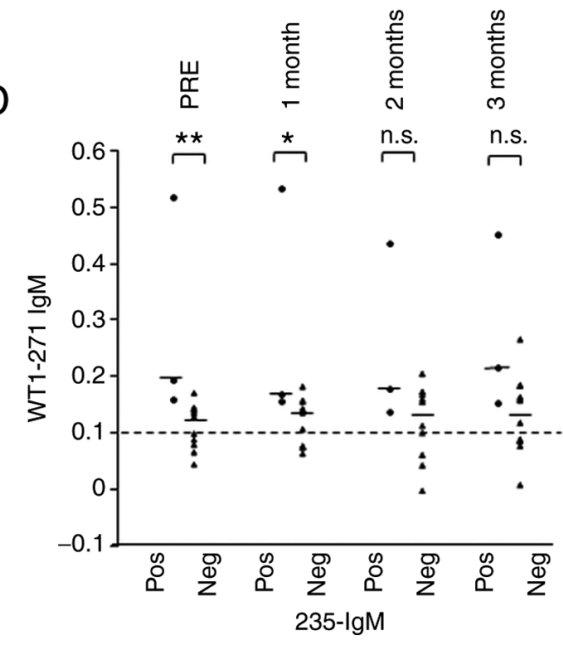

Figure 3. Immune recognition of WT1 antigens prior to vaccination. (A) Serum WT1-332-IgM and IgG antibody levels prior to vaccine treatment. (B) Serum WT1-271-IgM and IgG antibody levels at the indicated time-points of vaccine treatment. (C) A Venn diagram indicating positivity for WT1-235, -332 and -271 IgM and IgG antibodies prior to vaccine treatment. (D) Association between WT1-271 IgM levels and positive or negative WT1-235 IgM production prior to vaccine treatment. Horizontal bars in $\mathrm{B}$ and $\mathrm{D}$ indicate the median value of the antibody titer. ${ }^{*} \mathrm{P}<0.05,{ }^{* *} \mathrm{P}<0.01 ;$ n.s., not significant. Neg, negative; Pos, positive; Up, upregulated; PRE, pre-treatment; M, months.

ii) WT1-235 IgM was negative prior to and after vaccination, but WT1 IgG became positive during the treatment protocol (WT1-235 IgM Neg/IgG Up; n=4); iii) both WT1-235 IgM and IgG became positive after vaccination (WT1-235 IgM Up/IgG $\mathrm{Up}$; $\mathrm{n}=1$ ); and iv) both WT1-235 $\operatorname{IgM}$ and $\mathrm{IgG}$ were negative prior to and after vaccination (WT1-235 IgM Neg/IgG Neg; $\mathrm{n}=7$ ). The levels of WT1-235 IgG and IgM in each patient from the different groups prior to and during the first three months of vaccine treatment are presented in Fig. 2B.

Immune recognition of WT1 antigens prior to vaccination with the WT1 peptide. As described above, four patients exhibited WT1-235 IgG production without the preceding WT1-235 IgM elevation during the first 3 months of vaccination, suggesting class switching to WT1-235 IgG prior to vaccination. To understand the humoral immune responses to WT1 antigens prior to the vaccine treatment, the production of $\operatorname{IgM}$ and $\operatorname{IgG}$ antibodies against two non-target WT1 epitopes, WT1-332 and WT1-271, was examined. The WT1-332 epitope is an HLA class II-binding helper T lymphocyte (HTL) epitope (35). The WT1-271 epitope is a newly identified immunogenic WT1 epitope with elevated serum WT1-271 IgG antibody levels in patients with intestinal cancers (Ito et al, unpublished data). The WT1-332 IgM antibody was detected in the serum of four (12.9\%) of the 31 patients, whereas the WT1-332 IgG antibody was undetectable in all patients prior to vaccination (Fig. 3A). Serum WT1-271 IgM antibody was detected in $20(64.5 \%)$ patients prior to vaccination. The WT1-271 IgG antibody was also positive in the serum of four $(12.9 \%)$ of the 31 patients prior to vaccine treatment (Fig. 3B). These results indicated that the immune system recognized the WT1 antigen prior to administration of the WT1-235 peptide vaccine in most patients. Due to the high positivity rate for WT1-271 IgM prior to vaccination, WT1-271 IgM and $\mathrm{IgG}$ production was analyzed after administering the WT1-235 vaccine. The WT1-271 IgM antibody remained positive during the 3 -month protocol treatment period in most patients at levels similar to those prior to vaccine treatment. The WT1-271 IgG antibody remained detectable but exhibited no significant elevation during the 3 -month treatment protocol.

Furthermore, the production of $\operatorname{IgM}$ and $\operatorname{IgG}$ antibodies against the three WT1 antigens prior to vaccine treatment was compared in each patient (Fig. 3C). WT1-271 IgM was detected in all patients with WT1-235 or WT1-332 IgM production 
A

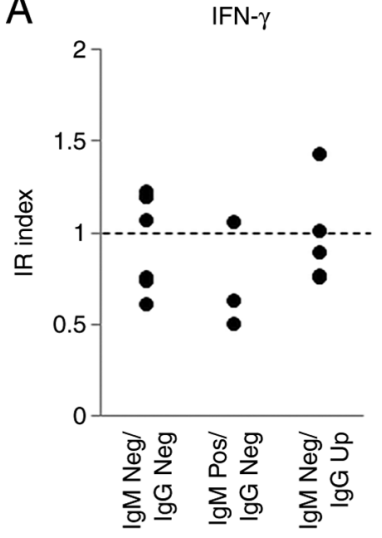

IL-10

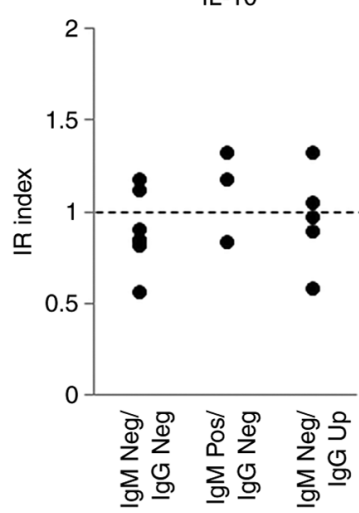

B

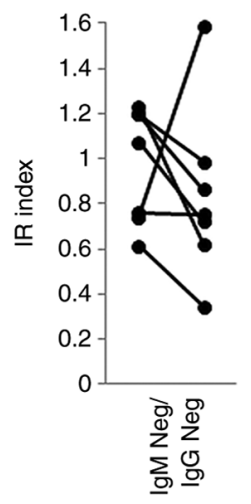

D
C

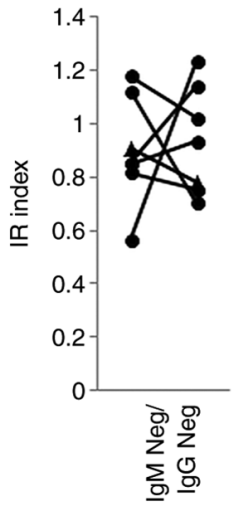

IL-10

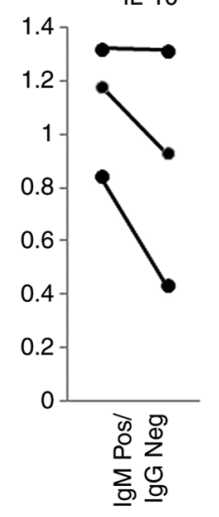

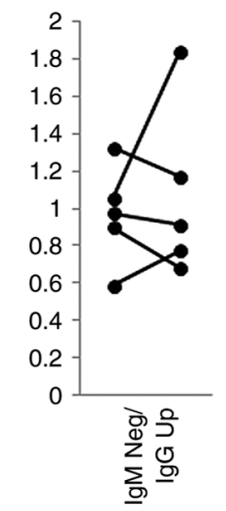

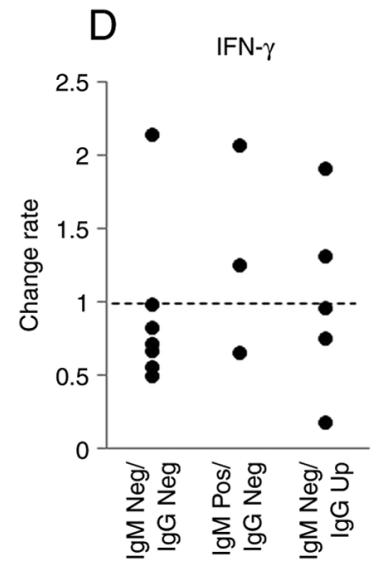

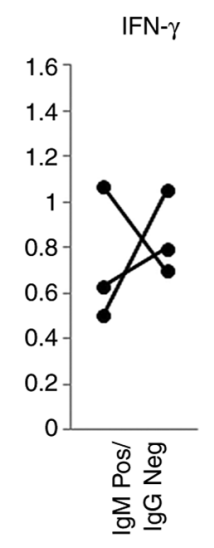

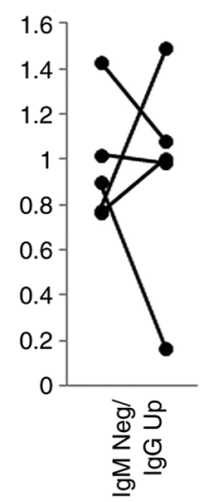

IL-10

Figure 4. Association between WT1-235 IgM antibody production prior to vaccination and WT1-235-specific cellular immune responses. Patients with positivity for WT1-235 IgM prior to treatment (n=3), negativity for WT1-235 IgM at the start and negativity for WT1-235 IgG during the 3 months of treatment $(\mathrm{n}=7)$, and negativity for WT1-235 IgM at the start and positivity for WT1-235 IgG during the 3 months of treatment (n=5) were analyzed for WT1-235-specific cellular immune responses as determined by the ELISPOT assay. (A) WT1-235-specific IFN- $\gamma$ and IL-10 production/secretion from PBMCs collected prior to vaccine treatment. The cutoff level (1.0) in the IR index for the positive detection of antigen-specific cytokine production/secretion in the ELISPOT assay is presented as a dotted line. (B) Changes in IFN- $\gamma$ production/secretion during the first month of vaccine treatment. (C) Changes in IL-10 production/secretion during the first month of vaccine treatment. (D) Rates of change in WT1-235-specific IFN- $\gamma$ and IL-10 production/secretion during the first month of vaccine treatment. Neg, negative; Pos, positive; Up, upregulated; IR, immune response.

prior to vaccination. In 15 patients, only WT1-271 IgM was detected. These results indicated that the immune system had already recognized and responded to the WT1 antigen in these patients, even if they were negative for WT1-235 IgM or WT1-332 IgM prior to the vaccine treatment.

Next, it was examined whether WT1-271 IgM antibody production was associated with WT1-235 epitope-specific IgM production prior to vaccine treatment. Serum WT1-271 IgM levels were significantly higher in the WT1-235 IgM-positive group than in the WT1-235 IgM-negative group at the start of and at 1 month after initiating vaccine treatment (Fig. 3D). These results indicated that WT1-235 IgM production was associated with WT1-271 IgM production in these tumor-bearing patients.

Association between WT1-235 antibody production and WT1-235-specific cellular immune responses. To characterize the immune responses in patients with positive WT1-235 IgM antibodies prior to vaccine treatment, WT1-235 epitope-specific IFN- $\gamma$ and IL-10 production/secretion by PBMCs from seven 235-IgM Neg/IgG Neg patients (patient IDs: 6, 10, 18, 25, 30, 32 and 33), three 235-IgM Pos/IgG Neg patients (patient IDs: 1, 13 and 22) and five 235-IgM Neg/IgG Up patients (patient IDs: 7,
14, 21, 28 and 29) were examined. No significant difference in WT1-235-specific IFN- $\gamma$ and IL-10 production/secretion was obtained with the ELISPOT assay prior to WT1-235 vaccine administration among the three patient groups (Fig. 4A). Next, the changes in IFN- $\gamma$ and IL-10 production/secretion were analyzed (Fig. 4B) and their rates of change were calculated by dividing their IR index at 1 month by the corresponding IR index prior to vaccine treatment. Of note, six of the seven 235-IgM Neg/IgG Neg patients exhibited a decrease in IFN- $\gamma$ production and secretion. All three patients with WT1-235 IgM antibody prior to vaccine treatment exhibited a decrease in IL-10 production and secretion in the first month (Fig. 4C).

Association between WT1 epitope-specific antibody production and clinical outcomes. The association between the production of WT1-235 and WT1-271 IgM antibodies prior to vaccine treatment and tumor progression during the treatment protocol was also analyzed. No significant association was observed between the production of these WT1 antibodies and clinical outcomes (Table II). However, a combination of WT1-235 and -271 IgM antibody positivity prior to treatment was significantly associated with unfavorable tumor control at 3 months after vaccine administration (Cramer's V=0.256; Table II). 
Table II. Association between WT1 IgM antibody and clinical outcomes.

\begin{tabular}{|c|c|c|c|}
\hline Antibody/status & Stable disease, $\mathrm{n}$ & Progressive disease, $\mathrm{n}$ & Statistical parameter \\
\hline WT1-235 IgM & & & $\mathrm{P}=0.432$ \\
\hline Positive & 0 & 3 & \\
\hline Negative & 4 & 19 & \\
\hline WT1-271 IgM & & & $\mathrm{P}=0.432$ \\
\hline Positive & 2 & 17 & \\
\hline Negative & 2 & 5 & \\
\hline WT1-235 IgM-WT1-271 IgM & & & Cramer's V $=0.256$ \\
\hline Positive-positive & 0 & 3 & \\
\hline Positive-negative & 2 & 14 & \\
\hline Negative-negative & 2 & 5 & \\
\hline
\end{tabular}

The association between initial WT1-235 and WT1-271 IgM antibody positivity and tumor control after 3 months of vaccine administration was analyzed using Fisher's exact probability test or Cramer's V-test.

\section{Discussion}

Sarcomas are a group of rare malignancies that have constrained the development of relevant therapeutic agents. WT1 is overexpressed in various types of sarcomas and may be considered a common target antigen for immunotherapy in these rare malignancies (36-38). In the present clinical trial for sarcomas, it was observed that administration of the WT1-235 peptide vaccine resulted in long-term stable disease in two patients with advanced STS. No standard treatment has been established for the majority of patients with advanced sarcomas. Furthermore, the effectiveness of immune checkpoint inhibitors for treating STS and bone sarcoma is limited $(39,40)$. Considering the currently limited therapeutic options, the WT1 peptide cancer vaccine may be considered a novel treatment option for sarcoma.

WT1-235 IgG antibody levels were elevated in five (33.3\%) of 15 patients during the 3 -month treatment protocol. A previous study by our group reported that the WT1-235 antibody levels were elevated in approximately half of the patients treated with the WT1-235 peptide cancer vaccine (29). These results suggested that only a small population of patients with sarcoma has elevated WT1-235 IgG antibodies. This low rate of WT1-235 IgG antibody elevation may indicate insufficient activity of WT1-specific helper T cells, which are required for class switching from $\operatorname{IgM}$ to $\mathrm{IgG}$. These suppressed immune responses may result from the advanced tumor stage and chemotherapies administered previously. In the present study, the production of antibodies against the WT1-332 helper epitope was analyzed and serum WT1-332 IgM antibodies were detected in four $(12.9 \%)$ of 31 patients; however, the WT1-332 IgG antibody was undetectable in all patients prior to vaccination. These results may indicate a lack of robust WT1-332-specific Th functions in these patients. A previous study by our group demonstrated that stimulation with the WT1-332 helper peptide enhanced the induction of WT1-235-specific cytotoxic T lymphocytes (CTLs) in vitro (35). Furthermore, a clinical trial on patients with recurrent glioblastoma multiforme indicated that the WT1-332 HTL peptide may be safely combined with the WT1-235 peptide (41). However, future clinical studies are required to examine whether a novel type of WT1 peptide vaccine including both
WT1-235 CTL and WT1-332 HTL peptides may induce more robust WT1-specific antitumor immune responses and achieve improved clinical effects in patients with sarcoma.

The present study provided several noteworthy findings on WT1-235-specific humoral immune responses. Although IgM generally precedes IgG antibody production in infectious diseases, prior elevation of WT1-235 IgM was observed in only one patient but not in the remaining four of five patients who exhibited an increase in WT1-235 IgG antibodies during the 3 months of treatment. These results indicated that a significant number of patients had already experienced class switching of WT1-235-specific B cells in patients with undetectable WT1-235 IgG prior to vaccination.

Furthermore, the WT1-235 IgM antibody was detected prior to vaccination in three patients. WT1-235 IgM antibody levels were detected at similar levels and WT1-235 IgG remained undetectable during the 3-month treatment period in all three patients. This lack of class switching to WT1-235 IgG indicated insufficient WT1-specific Th-cell assistance, suggesting that the presence of WT1-235 $\operatorname{IgM}$ antibody prior to vaccine treatment may be linked to unfavorable clinical outcomes, as the Th response has an essential role in the induction and maintenance of anti-tumor CTL responses. This is comparable with the results of the present study indicating that WT1-235 IgM was undetectable prior to vaccine administration in two patients who achieved long-term stable disease. Furthermore, the combination of WT1-235 and WT1-271 IgM antibody positivity was moderately associated with unfavorable tumor control. In addition, patients with WT1-235 IgM antibody prior to vaccine treatment tended to exhibit a decline in IL-10 production and secretion in the first month of vaccine treatment. This may explain the unfavorable clinical outcomes in patients with WT1-235 IgM antibodies, as IL-10 has crucial roles in the development and function of CD8 T-cell memory (42) and the stimulation of natural killer cells (43-46). Due to the small number of patients and the heterogeneity of diseases in the present study, it is necessary to examine whether IgM antibody production against the target antigen prior to vaccination may indicate a lack of robustness in Th responses and correlate with poor prognosis in the future. In recent years, 
neoantigens have been identified in different patients as targets for personalized medicine and a therapeutic peptide vaccine targeting these antigens has been considered to be a promising therapeutic option (47). In such settings, the measurement of IgM antibodies against target antigens may help evaluate antigen-specific Th responses in each patient and contribute to the selection of antigen peptides with high clinical potential.

Cancer therapeutic vaccines induce anti-tumor immune responses through the activation of cancer antigen-specific cytotoxic progenitor cells. Therefore, predicting whether the patient immune system is able to recognize and respond to the target antigen prior to immunotherapy is essential for individualized therapy. The present study indicated that the patient population with negative WT1-235 IgM and IgG prior to WT1-235 vaccine treatment included both patients with class WT1-235 IgG and those with undetectable WT1-235 IgM and IgG during the 3-month treatment. These results indicated that antibodies against the WT1-235 epitope alone cannot be used to assess the response of the patient's immune system to the WT1 antigen. The present study suggested that WT1-271 IgM antibody levels were elevated in $64.5 \%$ of patients, which was much higher than the frequency of WT1-235 $\operatorname{IgM}(9.6 \%)$ and WT1-332 IgM (12.9\%). All patients with positive WT1-235 IgM were also positive for WT1-271 IgM prior to vaccine treatment. These results indicate that the WT1-271 IgM antibody may be a marker for WT1-experienced B-cell immunity. Furthermore, a combination of WT1-235 and WT1-271 IgM antibody positivity was associated with unfavorable tumor control. Taken together, the WT1-271 IgM antibody may be helpful in the assessment of antitumor immunity in patients with cancer, as the presence of WT1-directed immunity indicates the potential of inducing antitumor immune responses against WT1.

Recently, multiple studies have reported the double-faceted roles of B lymphocytes, in addition to antibody production, in pro- and anti-tumor immunity (48). B cells may have pro-tumorigenic roles through the production and secretion of immunosuppressive cytokines, such as IL-10 $(49,50)$, TGF- $\beta$ (51) and IL-35 (52), and the induction of apoptosis in CD4+ T cells through the Fas-FasL system (50). In addition, B cells may have anti-tumorigenic roles through IFN- $\gamma$ secretion to enhance tumor killing by NK cells and CTLs $(50,53)$ and even kill tumor cells directly via the Fas-FasL system (51). WT1-235 target epitope-specific IgG production was thus analyzed in patients with recurrent glioblastoma treated with the WT1 peptide vaccine to monitor WT1-specific Th functions. The results indicated that WT1-235 IgG antibody production during vaccine treatment was associated with favorable clinical outcomes (29). In the present study, the findings suggested an association between WT1-235 IgM antibody production and WT1-235-specific cellular immune responses in the first month of WT1-235 vaccine treatment. As IgM production does not require Th-mediated class switching, WT1-235 IgM, rather than WT1-235 IgG, may be more directly associated with B-cell functions in cellular immune responses. Future studies are thus required on WT1-specific B-cell functions, such as immunomodulation through Th1 or Th2 cytokines.

WT1-235 IgG antibodies may contribute to WT1-235-specific cellular immune responses as an opsonin. Antibody-mediated opsonization of the cancer antigen MAGE-A3 reportedly promotes its uptake by dendritic cells. Furthermore, the stimulation of native T cells with antibody-opsonized MAGE-A3 protein induces a CD8 T-cell response rather than a CD4 T-cell response, indicating the existence of an uptake route-dependent mechanism by which subsequent immune responses are modulated (54). Similarly, WT1-235 IgG antibodies may bind to the WT1-235 peptide administered for vaccination, acting as an opsonin to promote subsequent WT1-specific cellular immune responses. This potential effect of WT1-235 IgG antibodies may explain the association between WT1-235 IgG production and the favorable clinical outcomes in patients with recurrent glioblastoma treated with the WT1-235 peptide vaccine that were previously reported by our group (29).

Approximately $10 \%$ of the patients with sarcoma that were assessed produced WT1-235 IgM and the majority produced WT1-271 IgM antibodies prior to the initiation of vaccination. These WT1 antibodies may exert direct anti-tumor effects on tumor cells expressing WT1 antigens on their cell surface. However, the WT1 protein localizes predominantly to the cytoplasm and is undetectable on tumor cell surfaces. Furthermore, the direct binding of WT1-235 and WT1-271 IgM antibodies to tumor cells may result in tumor destruction through activation of complement cascades existing in the tumor microenvironment (55). The association between WT1-235 and WT1-271 IgM antibodies and unfavorable clinical outcomes in the present study indicates that the direct action of these WT1 antibodies against tumor cells is unlikely in these patients.

Another possible effect of WT1 IgM antibodies is the modulation of B-cell functions through the $\operatorname{IgM}$ receptor, $\mathrm{F} c \mu \mathrm{R}$, abundantly expressed in B cells $(56,57)$. $\mathrm{Fc} \mu \mathrm{R}$ promotes $\mathrm{B}$-cell activation by interacting with the B-cell receptor (BCR) to enhance BCR signaling $(58,59)$. A common feature of $\mathrm{Fc} \mu \mathrm{R}$ deletion in mice is the production of autoreactive antibodies $(60,61)$, suggesting the involvement of $\mathrm{Fc} \mu \mathrm{R}$ in regulating B-cell tolerance. WT1-specific IgM antibodies are persistently produced in patients with WT1-expressing tumors. Further studies are required to examine whether these WT1-specific IgM antibodies modulate B-cell functions by binding to $\mathrm{Fc} \mu \mathrm{R}$ in patients treated with the WT1 peptide vaccine. Overall, the present results indicated that WT1 epitope-specific IgG and IgM antibodies may be helpful as immune-monitoring markers for WT1 peptide cancer vaccine immunotherapy.

\section{Acknowledgements}

The authors would like to thank Dr Seiji Hayashi (Kinki National Hospital, Sakai, Japan) and Dr Hiroshi Matsuoka (Division of Medical Oncology/Hematology, Department of Medicine, Kobe University Graduate School of Medicine, Kobe, Japan) for their support as Effect Safety Evaluation Committee members for the clinical study. The authors would also like to thank Ms. Tomoe Umeda and Ms. Chiaki Ohta (Osaka University Graduate School of Medicine, Department of Cancer Immunotherapy, Suita, Japan) for their contribution to patient enrolment and technical support in this study.

\section{Funding}

This study was supported by a grant from the Ministry of Education, Culture, Sports, Science and Technology, Japan (grant no. 20K08732). 


\section{Availability of data and materials}

The datasets used and/or analyzed during the current study are available from the corresponding author upon reasonable request.

\section{Authors' contributions}

SA designed this study, performed the experiments and data analysis and prepared the manuscript. NN, KH, NH, HO, EM, JN, SN, AT, YOk, HS and YOj designed and performed the clinical trial. HN contributed to the clinical trial through quality control and preparation of WT1 peptide vaccine, and acquisition and interpretation of clinical data. MK, MA, RI and MI performed the sample preparation, ELISPOT assay experiments and data analysis. FF, SM and SN performed data analysis. YOj designed this study, supervised the experiments, performed data analysis and prepared the manuscript. SA and YOk confirm the authenticity of all the raw data. All authors have read and approved the final manuscript.

\section{Ethics approval and consent to participate}

All patients provided written informed consent prior to participation in the study. The study protocol was approved by the Ethical Committee of Osaka University Hospital (nos. 07094 and 13386 for the clinical trials and no. 11293 for clinical sample analysis). Trials were registered at the UMIN Clinical Trials Registry as Umin000002001 and then UMIN000015997.

\section{Patient consent for publication}

Not applicable.

\section{Competing interests}

The authors declare that they have no competing interests.

\section{References}

1. Mazanet R and Antman KH: Sarcomas of soft tissue and bone Cancer 68: 463-473, 1991.

2. Tawbi HA, Burgess M, Bolejack V, Van Tine BA, Schuetze SM, $\mathrm{Hu}$ J, D'Angelo S, Attia S, Riedel RF, Priebat DA, et al: Pembrolizumab in advanced soft-tissue sarcoma and bone sarcoma (SARC028): A multicentre, two-cohort, single-arm, open-label, phase 2 trial. Lancet Oncol 18: 1493-1501, 2017.

3. Shoushtari AN, Van Tine BA and Schwartz GK: Novel treatment targets in sarcoma: More than just the GIST. Am Soc Clin Oncol Educ Book: e488-e495, 2014.

4. Saerens M, Brusselaers N, Rottey S, Decruyenaere A, Creytens D and Lapeire L: Immune checkpoint inhibitors in treatment of soft-tissue sarcoma: A systematic review and meta-analysis. Eur J Cancer 152: 165-182, 2021.

5. Keung EZ, Lazar AJ, Torres KE, Wang WL, Cormier JN, Ashleigh Guadagnolo B, Bishop AJ, Lin H, Hunt KK, Bird J, et al: Phase II study of neoadjuvant checkpoint blockade in patients with surgically resectable undifferentiated pleomorphic sarcoma and dedifferentiated liposarcoma. BMC Cancer 18: 913, 2018.

6. Ramachandran I, Lowther DE, Dryer-Minnerly R, Wang R, Fayngerts S, Nunez D, Betts G, Bath N, Tipping AJ, Melchiori L, et al: Systemic and local immunity following adoptive transfer of NY-ESO-1 SPEAR T cells in synovial sarcoma. J Immunother Cancer 7: 276, 2019.
7. Inoue K, Tamaki H, Ogawa H, Oka Y, Soma T, Tatekawa T, Oji Y, Tsuboi A, Kim EH, Kawakami M, et al: Wilms' tumor gene (WT1) competes with differentiation-inducing signal in hematopoietic progenitor cells. Blood 91: 2969-2976, 1998.

8. Sugiyama H: Cancer immunotherapy targeting WT1 protein. Int J Hematol 76: 127-132, 2002.

9. Oka Y, Tsuboi A, Kawakami M, Elisseeva OA, Nakajima H, Udaka K, Kawase I, Oji Y and Sugiyama H: Development of WT1 peptide cancer vaccine against hematopoietic malignancies and solid cancers. Curr Med Chem 13: 2345-2352, 2006.

10. Oji Y, Kitamura Y, Kamino E, Kitano A, Sawabata N, Inoue M, Mori M, Nakatsuka S, Sakaguchi N, Miyazaki K, et al: WT1 IgG antibody for early detection of nonsmall cell lung cancer and as its prognostic factor. Int J Cancer 125: 381-387, 2009.

11. Oji Y, Yamamoto H, Nomura M, Nakano Y, Ikeba A, Nakatsuka S, Abeno S, Kiyotoh E, Jomgeow T, Sekimoto M, et al: Overexpression of the Wilms' tumor gene WT1 in colorectal adenocarcinoma. Cancer Sci 94: 712-717, 2003.

12. Nakatsuka S, Oji Y, Horiuchi T, Kanda T, Kitagawa M, Takeuchi T, Kawano K, Kuwae Y, Yamauchi A, Okumura M, et al: Immunohistochemical detection of WT1 protein in a variety of cancer cells. Mod Pathol 19: 804-814, 2006.

13. Sugiyama H: Wilms' tumor gene WT1: Its oncogenic function and clinical application. Int J Hematol 73: 177-187, 2001.

14. Cheever MA, Allison JP, Ferris AS, Finn OJ, Hastings BM, Hecht TT, Mellman I, Prindiville SA, Viner JL, Weiner LM and Matrisian LM: The prioritization of cancer antigens: A national cancer institute pilot project for the acceleration of translational research. Clin Cancer Res 15: 5323-5337, 2009.

15. Oka Y, Tsuboi A, Taguchi T, Osaki T, Kyo T, Nakajima H, Elisseeva OA, Oji Y, Kawakami M, Ikegame K, et al: Induction of WT1 (Wilms' tumor gene)-specific cytotoxic T lymphocytes by WT1 peptide vaccine and the resultant cancer regression. Proc Natl Acad Sci USA 101: 13885-13890, 2004.

16. Izumoto S, Tsuboi A, Oka Y, Suzuki T, Hashiba T, Kagawa N, Hashimoto N, Maruno M, Elisseeva OA, Shirakata T, et al: Phase II clinical trial of Wilms tumor 1 peptide vaccination for patients with recurrent glioblastoma multiforme. J Neurosurg 108: 963-971, 2008.

17. Keilholz U, Letsch A, Busse A, Asemissen AM, Bauer S, Blau IW, Hofmann WK, Uharek L, Thiel E and Scheibenbogen C: A clinical and immunologic phase 2 trial of Wilms tumor gene product 1 (WT1) peptide vaccination in patients with AML and MDS. Blood 113: 6541-6548, 2009.

18. Oji Y, Oka Y, Nishida S, Tsuboi A, Kawakami M, Shirakata T, Takahashi K, Murao A, Nakajima H, Narita M, et al: WT1 peptide vaccine induces reduction in minimal residual disease in an imatinib-treated CML patient. Eur J Haematol 85: 358-360, 2010.

19. Hashii Y, Sato-Miyashita E, Matsumura R, Kusuki S, Yoshida H, Ohta H, Hosen N, Tsuboi A, Oji Y, Oka Y, et al: WT1 peptide vaccination following allogeneic stem cell transplantation in pediatric leukemic patients with high risk for relapse: Successful maintenance of durable remission. Leukemia 26: 530-532, 2012.

20. Maeda T, Hosen N, Fukushima K, Tsuboi A, Morimoto S, Matsui T, Sata H, Fujita J, Hasegawa K, Nishida S, et al: Maintenance of complete remission after allogeneic stem cell transplantation in leukemia patients treated with Wilms tumor 1 peptide vaccine. Blood Cancer J 3: e130, 2013.

21. Miyatake T, Ueda Y, Morimoto A, Enomoto T, Nishida S, Shirakata T, Oka Y, Tsuboi A, Oji Y, Hosen N, et al: WT1 peptide immunotherapy for gynecologic malignancies resistant to conventional therapies: A phase II trial. J Cancer Res Clin Oncol 139: 457-463, 2013.

22. Oji Y, Inoue M, Takeda Y, Hosen N, Shintani Y, Kawakami M, Harada T, Murakami Y, Iwai M, Fukuda M, et al: WT1 peptide-based immunotherapy for advanced thymic epithelial malignancies. Int J Cancer 142: 2375-2382, 2018.

23. Nishida S, Ishikawa T, Egawa S, Koido S, Yanagimoto H, Ishii J, Kanno Y, Kokura S, Yasuda H, Oba MS, et al: Combination gemcitabine and WT1 peptide vaccination improves progression-free survival in advanced pancreatic ductal adenocarcinoma: A phase II randomized study. Cancer Immunol Res 6: 320-331, 2018.

24. Maslak PG, Dao T, Bernal Y, Chanel SM, Zhang R, Frattini M, Rosenblat T, Jurcic JG, Brentjens RJ, Arcila ME, et al: Phase 2 trial of a multivalent WT1 peptide vaccine (galinpepimut-S) in acute myeloid leukemia. Blood Adv 2: 224-234, 2018.

25. Yanagisawa R, Koizumi T, Koya T, Sano K, Koido S, Nagai K, Kobayashi M, Okamoto M, Sugiyama H and Shimodaira S: WT1-pulsed dendritic cell vaccine combined with chemotherapy for resected pancreatic cancer in a phase I study. Anticancer Res 38: 2217-2225, 2018. 
26. Anguille S, Van de Velde AL, Smits EL, Van Tendeloo VF, Juliusson G, Cools N, Nijs G, Stein B, Lion E, Van Driessche A, et al: Dendritic cell vaccination as postremission treatment to prevent or delay relapse in acute myeloid leukemia. Blood 130: 1713-1721, 2017.

27. Ochi T, Fujiwara H, Okamoto S, An J, Nagai K, Shirakata T, Mineno J, Kuzushima K, Shiku H and Yasukawa M: Novel adoptive T-cell immunotherapy using a WT1-specific TCR vector encoding silencers for endogenous TCRs shows marked antileukemia reactivity and safety. Blood 118: 1495-1503, 2011.

28. Chapuis AG, Egan DN, Bar M, Schmitt TM, McAfee MS Paulson KG, Voillet V, Gottardo R, Ragnarsson GB, Bleakley $\mathrm{M}$, et al: T cell receptor gene therapy targeting WT1 prevents acute myeloid leukemia relapse post-transplant. Nat Med 25: 1064-1072, 2019

29. Oji Y, Hashimoto N, Tsuboi A, Murakami Y, Iwai M, Kagawa N, Chiba Y, Izumoto S, Elisseeva O, Ichinohasama R, et al: Association of WT1 IgG antibody against WT1 peptide with prolonged survival in glioblastoma multiforme patients vaccinated with WT1 peptide. Int J Cancer 139: 1391-1401, 2016

30. Petitprez F, de Reyniès A, Keung EZ, Chen TW, Sun CM, Calderaro J, Jeng YM, Hsiao LP, Lacroix L, Bougoüin A, et al: B cells are associated with survival and immunotherapy response in sarcoma. Nature 577: 556-560, 2020.

31. Schulz KF, Altman DG and Moher D; CONSORT Group: CONSORT 2010 Statement: Updated guidelines for reporting parallel group randomised trials. BMJ 340: c332, 2010.

32. Therasse P, Arbuck SG, Eisenhauer EA, Wanders J, Kaplan RS, Rubinstein L, Verweij J, Van Glabbeke M, van Oosterom AT, Christian MC and Gwyther SG: New guidelines to evaluate the response to treatment in solid tumors. European Organization for Research and Treatment of Cancer, National Cancer Institute of the United States, National Cancer Institute of Canada. J Nat Cancer Inst 92: 205-216, 2000

33. Trotti A, Colevas AD, Setser A, Rusch V, Jaques D, Budach V, Langer C, Murphy B, Cumberlin R, Coleman CN and Rubin P. CTCAE v3.0: Development of a comprehensive grading system for the adverse effects of cancer treatment. Semin Radiat Oncol 13: 176-181, 2003.

34. Hayashi S, Imanishi R, Adachi M,Ikejima S, Nakata J, Morimoto S, Fujiki F, Nishida S, Tsuboi A, Hosen N, et al: Reader-free ELISPOT assay for immuno-monitoring in peptide-based cancer vaccine immunotherapy. Biomed Rep 12: 244-250, 2020

35. Fujiki F, Oka Y, Tsuboi A, Kawakami M, Kawakatsu M, Nakajima H, Elisseeva OA, Harada Y, Ito K, Li Z, et al: Identification and characterization of a WT1 (Wilms Tumor Gene) protein-derived HLA-DRB1*0405-restricted 16-mer helper peptide that promotes the induction and activation of WT1-specific cytotoxic T lymphocytes. J Immunother 30: 282-293, 2007.

36. Ueda T, Oji Y, Naka N, Nakano Y, Takahashi E, Koga S, Asada M, Ikeba A, Nakatsuka S, Abeno S, et al: Overexpression of the Wilms' tumor gene WT1 in human bone and soft-tissue sarcomas. Cancer Sci 94: 271-276, 2003.

37. Sotobori T, Ueda T, Oji Y, Naka N, Araki N, Myoui A, Sugiyama $\mathrm{H}$ and Yoshikawa $\mathrm{H}$ : Prognostic significance of Wilms tumor gene (WT1) mRNA expression in soft tissue sarcoma. Cancer 106: 2233-2240, 2006

38. Oue T, Uehara S, Yamanaka H, Takama Y, Oji Y and Fukuzawa M: Expression of Wilms tumor 1 gene in a variety of pediatric tumors. J Pediatr Surg 46: 2233-2238, 2011.

39. Merchant MS, Wright M, Baird K, Wexler LH, RodriguezGalindo C, Bernstein D, Delbrook C, Lodish M, Bishop R, Wolchok JD, et al: Phase I clinical trial of ipilimumab in pediatric patients with advanced solid tumors. Clin Cancer Res 22: 1364-1370, 2016

40. Thanindratarn P, Dean DC, Nelson SD, Hornicek FJ and Duan Z: Advances in immune checkpoint inhibitors for bone sarcoma therapy. J Bone Oncol 15: 100221, 2019.

41. Tsuboi A, Hashimoto N, Fujiki F, Morimoto S, Kagawa N, Nakajima $H$, Hosen N, Nishida S, Nakata J, Morita S, et al: A phase I clinical study of a cocktail vaccine of Wilms' tumor 1 (WT1) HLA class I and II peptides for recurrent malignant glioma. Cancer Immunol Immunother 68: 331-340, 2019.

42. Foulds KE, Rotte MJ and Seder RA: IL-10 is required for optimal CD8 T cell memory following Listeria monocytogenes infection. J Immunol 177: 2565-2574, 2006.

43. Giovarelli M, Musiani P, Modesti A, Dellabona P, Casorati G Allione A, Consalvo M, Cavallo F, di Pierro F, De Giovanni C, et al: Local release of IL-10 by transfected mouse mammary adenocarcinoma cells does not suppress but enhances antitumor reaction and elicits a strong cytotoxic lymphocyte and antibody-dependent immune memory. J Immunol 155: 3112-3123, 1995.
44. Petersson M, Charo J, Salazar-Onfray F, Noffz G, Mohaupt M, Qin Z, Klein G, Blankenstein T and Kiessling R: Constitutive IL-10 production accounts for the high NK sensitivity, low MHC class I expression, and poor transporter associated with antigen processing (TAP)-1/2 function in the prototype NK target YAC-1. J Immunol 161: 2099-2105, 1998.

45. Fujiki F, Oka Y, Kawakatsu M, Tsuboi A, Tanaka-Harada Y, Hosen N, Nishida S, Shirakata T, Nakajima H, Tatsumi N, et al: A clear correlation between WT1-specific Th response and clinical response in WT1 CTL epitope vaccination. Anticancer Res 30: 2247-2254, 2010.

46. McKay K, Moore PC, Smoller BR and Hiatt KM: Association between natural killer cells and regression in melanocytic lesions. Hum Pathol 42: 1960-1964, 2011.

47. Blass E and Ott PA: Advances in the development of personalized neoantigen-based therapeutic cancer vaccines. Nat Rev Clin Oncol 18: 215-229, 2021.

48. Largeot A, Pagano G, Gonder S, Moussay E and Paggetti J: The B-side of cancer immunity: The underrated tune. Cells 8: 449, 2019.

49. Sarvaria A, Madrigal JA and Saudemont A: B cell regulation in cancer and anti-tumor immunity. Cell Mol Immunol 14: 662-674, 2017.

50. Tao H, Lu L, Xia Y, Dai F, Wang Y, Bao Y, Lundy SK, Ito F, Pan Q, Zhang X, et al: Antitumor effector B cells directly kill tumor cells via the Fas/FasL pathway and are regulated by IL-10. Eur J Immunol 45: 999-1009, 2015.

51. Olkhanud PB, Damdinsuren B, Bodogai M, Gress RE, Sen R, Wejksza K, Malchinkhuu E, Wersto RP and Biragyn A: Tumor-evoked regulatory B cells promote breast cancer metastasis by converting resting $\mathrm{CD}^{+}{ }^{+} \mathrm{T}$ cells to T-regulatory cells Cancer Res 71: 3505-3515, 2011.

52. Pylayeva-Gupta Y, Das S, Handler JS, Hajdu CH, Coffre M, Koralov SB and Bar-Sagi D: IL35-producing B cells promote the development of pancreatic neoplasia. Cancer Discov 6: 247-255, 2016.

53. Schwartz M, Zhang Y and Rosenblatt JD: B cell regulation of the anti-tumor response and role in carcinogenesis. J Immunother Cancer 4: 40, 2016.

54. Moeller I, Spagnoli GC, Finke J, Veelken H and Houet L: Uptake routes of tumor-antigen MAGE-A3 by dendritic cells determine priming of naive T-cell subtypes. Cancer Immunol Immunother 61: 2079-2090, 2012.

55. Roumenina LT, Daugan MV, Petitprez F, Sautes-Fridman C and Fridman WH: Context-dependent roles of complement in cancer. Nat Rev Cancer 19: 698-715, 2019.

56. Liu J, Wang Y, Xiong E, Hong R, Lu Q, Ohno H and Wang JY: Role of the IgM Fc receptor in immunity and tolerance. Front Immunol 10: 529, 2019.

57. Kubagawa H, Oka S, Kubagawa Y, Torii I, Takayama E, Kang DW, Gartland GL, Bertoli LF, Mori H, Takatsu H, et al: Identity of the elusive IgM Fc receptor (FcmuR) in humans. J Exp Med 206: 2779-2793, 2009.

58. Ouchida R, Mori H, Hase K, Takatsu H, Kurosaki T, Tokuhisa T, Ohno $\mathrm{H}$ and Wang JY: Critical role of the IgM Fc receptor in IgM homeostasis, B-cell survival, and humoral immune responses. Proc Natl Acad Sci USA 109: E2699-E2706, 2012.

59. Ouchida R, Lu Q, Liu J, Li Y, Chu Y, Tsubata T and Wang JY: $\mathrm{Fc} \mu \mathrm{R}$ interacts and cooperates with the $\mathrm{B}$ cell receptor To promote B cell survival. J Immunol 194: 3096-3101, 2015.

60. Honjo K, Kubagawa Y, Suzuki Y, Takagi M, Ohno H, Bucy RP, Izui S and Kubagawa H: Enhanced auto-antibody production and Mott cell formation in Fc $\mu$ R-deficient autoimmune mice. Int Immunol 26: 659-672, 2014.

61. Yu J, Duong VHH, Westphal K, Westphal A, Suwandi A, Grassl GA, Brand K, Chan AC, Föger N and Lee KH: Surface receptor Toso controls $\mathrm{B}$ cell-mediated regulation of $\mathrm{T}$ cell immunity. J Clin Invest 128: 1820-1836, 2018.

This work is licensed under a Creative Commons Attribution-NonCommercial-NoDerivatives 4.0 International (CC BY-NC-ND 4.0) License. 